\title{
KOKON: A Germany-Wide Collaborative Research Project to Identify Needs, Provide Information, Foster Communication and Support Decision-Making about Complementary and Alternative Medicine in Oncology
}

Güthlin, Corina ; Bartsch, Hans-Helge ; Joos, Stefanie ; Längler, Alfred ; Lampert, Claudia ; Ritter, Christoph ; Schildmann, Jan ; Weis, Joachim ; Wilhelm, Martin ; Witt, Claudia M ; Horneber, Markus

\begin{abstract}
Background: The German Cancer Aid set up a priority research programme with the intention to generate high-quality information based on evidence and to make this information easily accessible for health-care professionals and advisors, researchers, patients, and the general public. Summary: The Kompetenznetz Komplementärmedizin in der Onkologie (KOKON) received 2 funding periods within this programme. During the first funding period, KOKON assessed patients' and health-care professionals' informational needs, developed a consulting manual for physicians, developed an education programme for self-help groups, set up a knowledge database, and developed a pilot information website for patients. Funding period 2 continues with work that allows cancer patients and health-care professionals to make informed decisions about complementary and alternative medicine (CAM). For this aim, KOKON evaluates training programmes for physicians (oncology physicians, paediatric oncologists, and general practitioners) and for self-help groups. All training programmes integrate results from an analysis of the ethical, psychological, and medical challenges of CAM in the medical encounter, and the knowledge database is being extended with issues related to CAM for supportive and palliative care. Key Message: A Germany-wide collaborative research project to identify needs, provide information, foster communication, and support decision-making about CAM in oncology is being set up.
\end{abstract}

DOI: https://doi.org/10.1159/000502945

Posted at the Zurich Open Repository and Archive, University of Zurich

ZORA URL: https://doi.org/10.5167/uzh-198901

Journal Article

Published Version

Originally published at:

Güthlin, Corina; Bartsch, Hans-Helge; Joos, Stefanie; Längler, Alfred; Lampert, Claudia; Ritter, Christoph; Schildmann, Jan; Weis, Joachim; Wilhelm, Martin; Witt, Claudia M; Horneber, Markus (2020). KOKON: A Germany-Wide Collaborative Research Project to Identify Needs, Provide Information, Foster Communication and Support Decision-Making about Complementary and Alternative Medicine in Oncology. Complementary Medicine Research, 27(2):105-111.

DOI: https://doi.org/10.1159/000502945 


\title{
KOKON: A Germany-Wide Collaborative Research Project to Identify Needs, Provide Information, Foster Communication and Support Decision-Making about Complementary and Alternative Medicine in Oncology
}

\author{
Corina Güthlin $^{\mathrm{a}}$ Hans-Helge Bartsch $^{\mathrm{b}}$ Stefanie Joos ${ }^{c}$ Alfred Längler $^{\mathrm{d}}$ Claudia Lampert $^{\mathrm{e}}$ \\ Christoph Ritter $^{\mathrm{f}} \quad$ Jan Schildmann $^{\mathrm{g}} \quad$ Joachim Weis $^{\mathrm{h}}$ Martin Wilhelm $^{\mathrm{j}} \quad$ Claudia M. Witt $^{\mathrm{k}}$ \\ Markus Horneber ${ }^{i, j}$ \\ ${ }^{a}$ Institute for General Practice, Goethe University, Frankfurt, Germany; ${ }^{\text {b } K l i n i k ~ f u ̈ r ~ O n k o l o g i s c h e ~ R e h a b i l i t a t i o n, ~}$ \\ Universitätsklinikum Freiburg, Freiburg, Germany; ${ }^{C}$ Institute for General Practice, University Hospital, Tübingen, \\ Germany; ${ }^{d}$ Gemeinschaftskrankenhaus, Witten-Herdecke, Germany; ${ }^{e}$ Hans Bredow Institute, Hamburg, Germany; \\ ${ }^{f}$ Klinische Pharmazie, Universität Greifswald, Greifswald, Germany; ${ }^{9}$ Institut für Geschichte und Ethik der Medizin, \\ Martin-Luther-Universität, Halle-Wittenberg, Germany; ${ }^{\text {h}}$ Department of Cancer Self-Help Research, Comprehensive \\ Cancer Center, Medical Center - University Clinic Center, Freiburg, Germany; 'Universitätskliniken für Innere Medizin \\ 3 und 5, Schwerpunkte Pneumologie und Onkologie/Hämatologie, Paracelsus Medizinische Privatuniversität, \\ Klinikum Nürnberg, Nürnberg, Germany; ${ }^{j}$ Paracelsus Medizinische Privatuniversität, Klinikum Nürnberg, Nürnberg, \\ Germany; ${ }^{k}$ Department for Epidemiology and Health Economics, Charité, Berlin, Germany
}

\section{Keywords}

Complementary and alternative medicine · Oncology ·

Information and communication

\begin{abstract}
Background: The German Cancer Aid set up a priority research programme with the intention to generate highquality information based on evidence and to make this information easily accessible for health-care professionals and advisors, researchers, patients, and the general public. Summary: The Kompetenznetz Komplementärmedizin in der Onkologie (KOKON) received 2 funding periods within this programme. During the first funding period, KOKON assessed patients' and health-care professionals' informational needs, developed a consulting manual for physicians, developed an education programme for self-help groups, set
\end{abstract}

up a knowledge database, and developed a pilot information website for patients. Funding period 2 continues with work that allows cancer patients and health-care professionals to make informed decisions about complementary and alternative medicine (CAM). For this aim, KOKON evaluates training programmes for physicians (oncology physicians, paediatric oncologists, and general practitioners) and for self-help groups. All training programmes integrate results from an analysis of the ethical, psychological, and medical challenges of CAM in the medical encounter, and the knowledge database is being extended with issues related to CAM for supportive and palliative care. Key Message: A Germanywide collaborative research project to identify needs, provide information, foster communication, and support decision-making about CAM in oncology is being set up.

() 2019 S. Karger AG, Basel 


\section{KOKON: Ein deutschlandweites \\ Verbundforschungsprojekt, um Bedarf bezüglich \\ Komplementärmedizin in der Onkologie zu \\ identifizieren, entsprechende Informationen zur \\ Verfügung zu stellen sowie Kommunikation und \\ Entscheidungsfindung zu befördern}

\section{Schlüsselwörter}

Komplementärmedizin · Onkologie · Information and

Kommunikation

\section{Zusammenfassung \\ Hintergrund: Die Deutsche Krebshilfe hatte ein soge-} nanntes "Priority Research Programme" ausgeschrieben, in dem evidenzbasierte Informationen von höchster Qualität für Angehörige von Gesundheitsberufen und für Berater, Forscher, Patienten und die Öffentlichkeit zugänglich gemacht werden sollten. Zusammenfassung: Das Kompetenznetz Komplementärmedizin in der Onkologie (KOKON) konnte Fördergelder für zwei Förderperioden innerhalb dieses Programms akquirieren. KOKON untersuchte in der ersten Förderperiode den Bedarf von Patienten und Angehörigen von Gesundheitsberufen sowie Informationsbedürfnisse, entwickelte ein Konsultationsmanual für Ärzte, ein Trainingsprogramm für Selbsthilfegruppen, baute eine Wissensdatenbank auf und entwickelte eine Pilot-Informations-Webseite für Patienten. In Förderperiode 2 wurde diese Arbeit insofern fortgesetzt, als dass Patienten und Angehörige von Gesundheitsberufen in die Lage versetzt werden sollten, informierte Entscheidungen zu treffen. Zu diesem Zweck evaluiert KOKON Trainingsprogramme für Ärzte (aus der Onkologie, Kinderonkologen und Hausärzte) und für Selbsthilfe-Gruppen. Alle Trainingsprogramme integrieren Ergebnisse von Analysen der ethischen, psychologischen und medizinischen Herausforderungen von Komplementärmedizin in der medizinischen Versorgung, und die Wissensdatenbank wird um Themen der Supportivund der Palliativ-Therapie erweitert. Schlussfolgerung: Ein deutschlandweiter Forschungsverbund konnte etabliert werden, um den Bedarf bezüglich Komplementärmedizin in der Onkologie zu identifizieren, entsprechende Informationen zur Verfügung zu stellen sowie Kommunikation und Entscheidungsfindung zu fördern.

(c) 2019 S. Karger AG, Basel

\section{Introduction}

Complementary and alternative medicine (CAM) is highly prevalent among cancer patients. A meta-analysis of epidemiological studies has shown that the prevalence of CAM use in cancer patients has increased steadily from $25 \%$ in the 1980 s to more than $49 \%$ since 2000 [1]. Similarly high rates can be found in paediatric oncology: depending on the study population and how CAM is defined, $12-85 \%$ of children are treated with it [2].

From the patient perspective, it is possible to distinguish between "push" and "pull" factors of CAM [3]. Pull factors include valuing CAM as a natural approach in which patients can play an active role, the sheer availability of CAM options, boosting of the immune system, reduction of the side effects of conventional treatment, and the belief that CAM can support both physical and psychological health [4].

In contrast, Wanchai et al. [5] identified perceived ineffectiveness and concerns about possible negative effects of standard treatment as well as unsatisfactory communication with doctors as push factors for CAM use in women with breast cancer. Taking those factors together, patients have a considerable need for information and guidance but often get frustrated about the diverging information and contradictory messages about the evidence of CAM [6]. Although patients want health professionals to be their primary point of contact for information and guidance about CAM, helpful communication is rare in the clinical encounter, in adult as well as in paediatric oncology $[4,7,8]$.

A systematic review of guidelines seeking to explain how doctors should discuss CAM with their patients came up with the following recommendations: (1) elicit the person's understanding of their situation; (2) respect cultural and linguistic diversity and different epistemological frameworks; (3) ask questions about CAM use at critical points in the illness trajectory; (4) explore details and listen actively; (5) respond to the person's emotional state; (6) discuss relevant concerns while respecting the person's beliefs; (7) provide balanced, evidence-based advice; (8) summarize discussions; (9) document the discussion; (10) monitor and follow up [9].

Findings from a clinician-led consultation service about CAM, funded by the German Cancer Aid since 1999, showed that a guideline-oriented, patient-centred approach provides physicians with the opportunity to engage in open and supportive dialogues about CAM to help with symptom management, psychological support, and individual self-care [10].

In response to this, the German Cancer Aid initiated the priority research programme "Complementary Medicine in Oncology" in 2010. The programme was intended to "generate high-quality information on existing practices and evidence-based studies as well as make this information easily accessible for health care professionals and advisors, researchers, patients and the general public."

Within this priority programme, 2 grants were awarded to Kompetenznetz Komplementärmedizin in der Onko- 
logie (KOKON) from 2012 to 2015 (funding period 1) and from 2016 to 2020 (funding period 2). KOKON is a multiprofessional Germany-wide collaborative research project with the aim to establish a "Competence Network for Complementary Medicine in Oncology." During funding period 1, KOKON consisted of 13 institutions, which successfully carried out comprehensive and collaborative projects within 6 research areas (Fig. 1) [11]. For the ongoing funding period 2 and its 7 research areas, KOKON extended its research network by institutions from paediatric oncology and pharmaceutic biology. In this paper, we briefly summarize the key findings from funding period 1 and subsequently describe the research programme of funding period 2 in more detail. We then discuss what KOKON's results and its multidisciplinary approach have contributed to the discussion about CAM in oncology, the challenges associated with this topic, and the difficulties of making resources available for the provision of evidence-based and patient-oriented information on CAM within standard oncologic care after the termination of the priority programme.

When it comes to communication projects in this area, it is important to say a word about the distinction between alternative and complementary medicine in the sense that it certainly is problematic to use CAM methods "as an alternative" to standard therapy (e.g., chemotherapy). Complementary methods, on the other hand, can be seen as less problematic when counteracting symptoms but not interfering with standard therapy. However, as interactions can apply, one should be cautious as well.

From a communication point of view, we think that one should not discourage patients but encourage them (e.g., to stay with the standard treatment). In some instances, it can also help to defocus patients from dubious methods by not telling them what they should do (e.g., "do not use 'alternative methods") but by understanding their motivation. As a result, we try to encourage conversations about what patients use and why they use what. We believe that this is the best basis for talking about CAM methods and their limits, irrespectively of the distinction between alternative and complementary medicine.

\section{Funding Period 1: Identifying Needs and Providing Information}

In funding period 1 , we set up the basis for information, communication, and training through the following:

\section{Needs Analysis among Patients and Health-Care \\ Professionals}

We investigated the need for information and communication about CAM in cancer patients by means of a media reception analysis [12], qualitative interviews, and

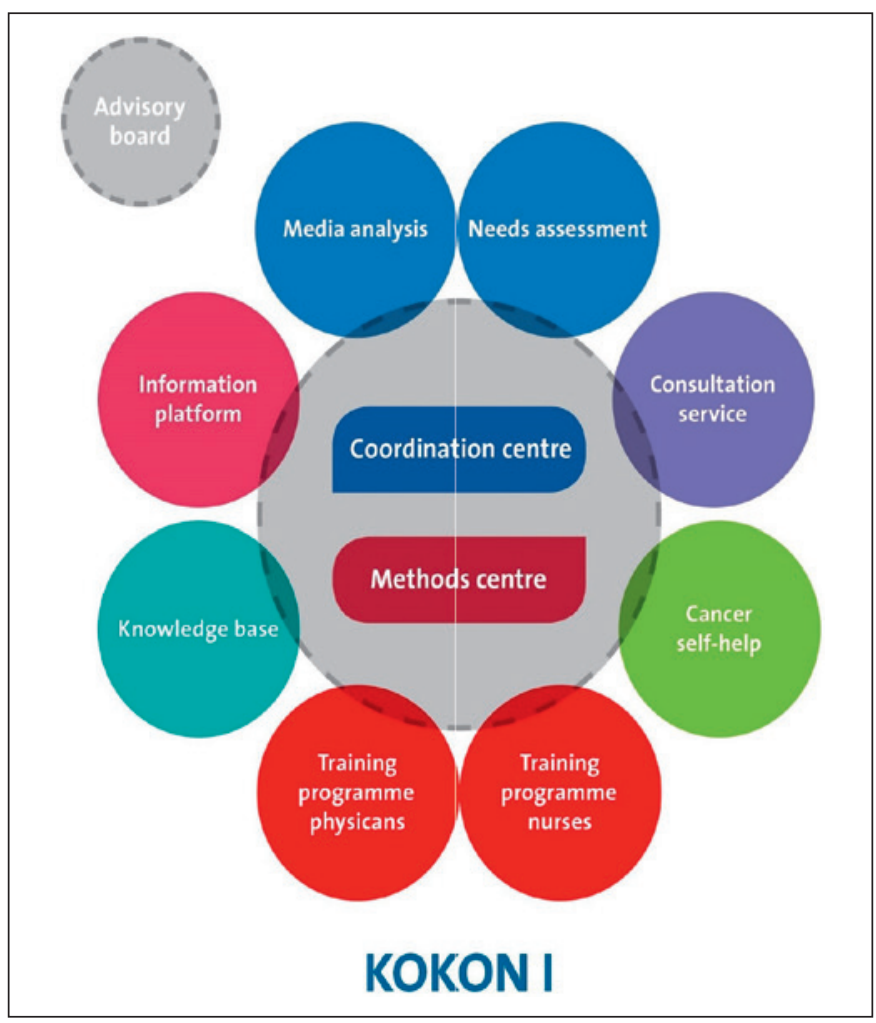

Fig. 1. Research areas in funding period 1.

a quantitative survey $[13,14]$ and assessed the need for information and training about CAM of health-care professionals working in oncology (physicians, nurses, psychologists, and social workers) through qualitative interviews and a quantitative survey $[15,16]$. Taken together, the findings underlined the importance which the topic CAM has for patients within the cancer journey and revealed a strong need for information and training about CAM in health professionals.

\section{Evaluation of Physician-Led Consultation Services}

We advanced the findings of a previous project [10] into a communication manual for a multicenter physician-led consultation service and implemented and evaluated the service at 7 cancer centres. Based on the manual, we developed a training programme for gynaecologists consulting cancer patients about CAM and tested the programme in a pilot randomized study [17].

\section{Setup of a Knowledge Database and Information Website}

To provide evidence-based information on CAM for KOKON's health professionals, we started to set up a knowledge database in close cooperation with the CAMCANCER project (originally funded by the European Commission within the Framework 5 Programme and now managed by the Norwegian National Research Center for 


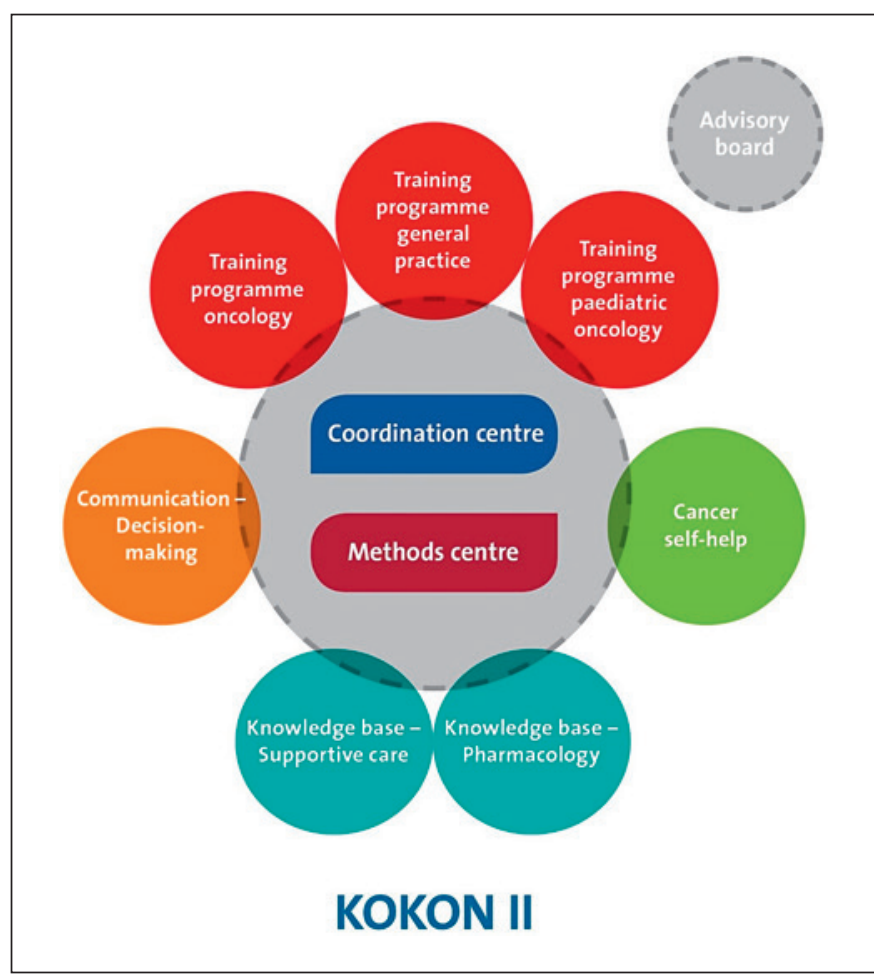

Fig. 2. Research areas in funding period 2.

Complementary and Alternative Medicine [NAFKAM]). For the content, we translated, updated, and published the monographs of CAM-CANCER on the platform "Onkopedia" of the DGHO (https://www.onkopedia.com). We furthermore compiled short summaries on a broad range of CAM topics and established a novel system to estimate the risk of herb-drug interactions based on a systematic synthesis of the available pharmacologic evidence $[18,19]$.

For cancer patients, we developed, tested, and launched a concept-based pilot version of an information website on CAM (https://www.kokoninfo.de).

\section{Evaluation of an Education Programme for Cancer \\ Self-Help Groups}

To strengthen and promote the competence of patients and relatives dealing with CAM, a modular educational programme was developed and tested. The first evaluation results indicate that the programme can assist cancer selfhelp group leaders in starting a structured discussion about CAM in their groups [Jablotschkin et al., in press].

\section{Funding Period 2: Supporting Communication and Decision-Making}

In funding period 2, KOKON follows up on the main themes developed in funding period 1 and extends its work in order to bring it to a level that allows informed decision-making about CAM in daily oncology practice. For this purpose, KOKON sets up and evaluates training programmes for the group of physicians that patients or their relatives usually ask for advice (oncology physicians, paediatric oncologists, and general practitioners [GPs]) and for self-help groups. All training programmes integrate results from an interdisciplinary analysis of the ethical, psychological, and medical challenges of CAM in the medical encounter. KOKON furthermore extends the knowledge database according to the results of the needs assessment in health-care professionals in funding period 1. Similarly to funding period $1, \mathrm{KOKON}$ consists of a multi-professional research team to meet the peculiarities of the research field with experts from oncology, general medicine, paediatrics, epidemiology, pharmacology, psychology, and medical ethics. Altogether, 7 projects are being carried out in 4 major research areas: (1) communication and decision-making, (2) training, (3) knowledge database, and (4) cancer self-help organizations (Fig. 2).

\section{Topic 1: Communication and Decision-Making}

This is a multi-professional project that involves oncology physicians, psychologists, and experts on medical ethics. The overall aim is to help oncologists, GPs, and paediatric oncologists to deal with advice being requested relating to CAM in a professional manner. For this purpose, conceptual as well as empirical research was conducted. Theoretical analysis focused on descriptive and normative criteria with which CAM is usually labelled and associated. Empirical research is used to explore health professionals' perceptions and views of the challenges they face when dealing with CAM in cancer. Based on this conceptual and empirical research, an interdisciplinary analysis of the ethical, psychological, and medical challenges of CAM is being conducted. Findings are used to develop concepts for communication and decisionmaking about CAM and to conduct workshops to train physicians. The project furthermore develops institutional strategies to deal with CAM in cancer care.

\section{Topic 2: Training Programmes}

(a) Training Programme for Oncology Physicians

A blended-learning training programme (KOKONKTO) consisting of nine 45-min e-learning units and a 2-day on-site skills workshop has been developed with the aim of teaching oncology physicians about CAM and how to advise their patients on the subject. To evaluate the training, 40 physicians will take part in a cluster-randomized trial, of whom some will have undergone the KOKON-KTO training and some will not. Within the study, physicians will each advise up to 10 patients. Effectiveness will be evaluated within 3 settings: after elearning, during skills training, and after physicians have provided advice to their patients [20]. 
(b) Training Programme for Paediatric Oncologists

Similarly to the training for oncology physicians, this training consists of a blended-learning programme (elearning modules and on-site skills training in which typical CAM consulting situations in paediatric oncology and in standard practice are simulated and discussed). The content of the e-learning materials is based on a survey of the training needs of paediatric oncologists. The content of the e-learning training modules was developed in cooperation with the other project groups within topic 2 and was supplemented with specific information relating to paediatric oncology. For this purpose, the scientific database KOKONbase that was developed in the first funding period has been updated with specific child information on paediatric oncology. The blended learning training will be evaluated by surveys and by studying communication situations using the Roter Interaction Analysis system [21].

\section{(c) Training Programme for GPs}

A blended-learning training programme for GPs has been developed together with the other groups and was adapted to the needs of GPs. It consists of e-learning modules that provide an overview of what is meant by CAM and why patients are interested in it, as well as evidence-based information on treating several core symptoms. In contrast to the other training programmes, a chapter on oncology treatments is also included. Analogous to the other training programmes, the e-learning phase is followed by an on-site skills workshop in which communication challenges are discussed and decisionmaking is trained on an individual basis. The evaluation consists of surveys and also studies communication situations using the Roter Interaction Analysis system [21].

\section{Topic 3: Knowledge Database}

(a) Efficacy and Safety of CAM for Supportive and

Palliative Care

This project aims to expand the knowledge database (KOKONbase) that was developed in the first funding period. For this purpose, the project team summarizes and synthesizes the best available evidence for CAM interventions for supportive and palliative care. All processes, including literature retrieval, appraisal, writing, and reviewing, follow systematic, predefined methods.

(b) Pharmacokinetic and Pharmacodynamic

Interactions of Herbal Drugs

The aim of this project is to present and estimate interaction potential for a representative spectrum of phytotherapeutical plant specimens used in supportive care for anticancer treatment. This includes pharmacokinetic as well as pharmacodynamic drug interaction mechanisms. The evaluation of pharmacodynamic herb-drug interactions will focus on synergistic hepatotoxicity, immunomodulation, and antioxidative antagonisms. Further, risk estimates are being developed for the use of phytotherapeutics in regimens with combinations of antineoplastic drugs. This project is carried out in close cooperation with the team evaluating the efficacy and safety of complementary medicine procedures for supportive anticancer care that was described in the previous paragraph. Each document will be peer-reviewed and cross-linked within the KOKON evidence database.

Through a collaboration with the Deutsche Gesellschaft für Hämatologie und Medizinische Onkologie, information from (a) and (b) will be easily accessible through the Onkopedia website (https://www.onkopedia. $\mathrm{com} / \mathrm{de} /$ onkopedia/guidelines) and will support all KOKON training programmes.

Topic 4: Educational Programme for Self-Help Groups

Self-help groups in cancer care offer nonprofessional psychosocial support to patients and cancer survivors. This includes providing information on cancer- and treatment-related topics and giving patients the opportunity to share their experiences with cancer and the healthcare system. CAM is one of many topics that is frequently discussed in self-help groups, but generally under considerable uncertainty with regard to the reliability of available information, and with a lack of guidance. The educational programme consists of 4 structured modules (overview of CAM in cancer, expectations, reliability and evidence, sources of information of assured quality). Train-the-trainer workshops are used to train group leaders to pass information on to their groups. The aim of this project is to implement the programme in cooperation with the largest cancer patient advocacy groups in Germany and to evaluate the training. We evaluate the trainthe-trainer workshops and the educational programmes with the group members. To analyse the effects of the educational programme, a follow-up assessment is carried out after 6 months.

\section{Discussion}

All projects in funding periods 1 and 2 aim to support cancer patients and health professionals to make informed decisions about the use of CAM. To achieve this aim, a number of challenges must be overcome. We would like to discuss 3 aspects that are of relevance:

\section{Multi- and Interdisciplinarity: What Is Required to}

Make Informed Decisions about CAM?

Work in KOKON draws from the expertise of a number of disciplines, such as oncology, epidemiology, paediatrics, psychology, pharmacology, nursing, and the me- 
dia. Such a multi-professional approach is clearly necessary to ensure that information provided on CAM in cancer care is well founded and to support informed decision-making on the subject in the future. While, for example, the development of a sound evidence base for CAM treatments requires the work of pharmacologists, clinical experts, and epidemiologists, the expertise of clinicians from a number of fields is necessary to develop trainings that take into account the particular contexts, needs, and perspectives of physicians specializing in different areas. Expertise in psychology and ethics helps the developers of training programmes to reflect critically upon the normative and communication requirements of such programmes, and collaboration with self-help groups fosters empowerment and self-care.

While experiences gathered in KOKON have shown that the best results are achieved when a multidisciplinary team works on the communication of CAM options in oncology, some challenges remain. This is because patients, relatives, representatives of self-help groups, and various medical disciplines have their own attitudes, needs, and wishes and are not always satisfied with information for which only scanty evidence exists. For this reason, all communication and training concepts, as well as the knowledge database (KOKONbase) and the information platform (KOKONinfo), explicitly account for communication challenges in everyday practice and give practical information that is always based on the best available evidence. However, whether patients benefit sufficiently from these concepts and trainings requires further investigation.

\section{Translation: From the Identification of Needs to the} Implementation and Evaluation of Effective Training

In addition and complementary to cancer patients' interest in receiving advice on CAM options, the KOKON network has explored the informational needs of health professionals engaged in cancer care $[12,15]$ and set up a pilot training programme accordingly [17]. The analysis of needs in the first funding period showed that it is necessary to provide health-care personnel and self-help groups with scientifically sound information on CAM treatments for cancer patients [15]. Sound information would address doctors' desire to have at their fingertips an overview of different CAM options for supportive and palliative cancer care. As patients' needs and attitudes are often influenced by the media, sound information might also help provide a more accurate picture of what CAM is and what it can be expected to achieve. However, in order to provide good quality information through the $\mathrm{KO}$ KON network, it was necessary to prepare structured scientific texts on treatment methods used in complementary medicine and provide evidence-based information on interactions between herbal substances and cancer medications. This was carried out in both the first and second funding periods and has led to the preparation of hundreds of texts on various substances and treatment options. Qualitative interviews conducted in the first funding period also made it clear that advising cancer patients on CAM is not solely a question of synthesizing available evidence but also presents doctors with important ethical and communicative challenges [16].

The translation of identified needs into support for health professionals and patients in clinical practice is the central aim of the second funding period. The development of blended-learning programmes that consist of elearning sessions and on-site workshops for oncology physicians, paediatric oncologists, and GPs requires the support of experts in the field, not only to identify the most important and relevant questions but also to provide high-quality training that is acceptable and interesting from the perspective of those working in the field. At the same time, KOKON's blended-learning programmes explicitly address the so-called communication gap of CAM in oncology [22]. In addition, the knowledge base including practical comments on how to interpret scarce evidence in the literature can be used to develop e-learning materials for upcoming training programmes. All training courses are currently being evaluated with respect to knowledge gain and communication skills. The clusterrandomized pilot trial from the first phase showed that training oncology physicians in providing advice during CAM-designated consultations scores highly for patient satisfaction and may be especially beneficial for physicians less experienced in CAM. However, physicians have reported that an additional consultation of around $45 \mathrm{~min}$ about CAM is too time-consuming [17]. The second will address this issue and train oncology physicians for a consultation format that fits better into everyday practice.

\section{Sustainability: How to Ensure the Implementation of KOKON's Results in Daily Practice}

Providing sustainable resources for informed decisionmaking on questions relating to CAM requires structures and processes that can exist independently of current funding. Currently, all projects develop their own strategies and formats to ensure sustainability, while taking into account their own specific requirements, e.g., the information base must be continuously updated to reflect new evidence as it emerges. This means that staff will be required to review new evidence, provide technical support, and update online materials. A different strategy is necessary for the training modules. There are different ways to achieve sustainability, such as by making the education manuals for the training programmes generally accessible (e.g., through professional associations) and by offering the training programmes as options in continuing medical education. Training programmes for oncology physicians and nurses will be implemented in some cancer centres in Germany. 


\section{Acknowledgement}

We would like to thank and acknowledge Phillip Elliott who edited the English version of the manuscript several times.

\section{Disclosure Statement}

The authors have no conflicts of interest to declare.

\section{Funding Sources}

The German Cancer Aid (Deutsche Krebshilfe [DKH]) funded both funding periods of KOKON (Funding Nos. 109863 and 70112369). The DKH did not participate in preparing the manuscript.

\section{Author Contributions}

C. Güthlin: conception of manuscript, drafting the manuscript, final approval.

H.-H. Bartsch: drafting the manuscript, final approval.

S. Joos: drafting the manuscript, final approval.

A. Längler: drafting the manuscript, final approval.

C. Lampert: drafting the manuscript, final approval.

C. Ritter: drafting the manuscript, final approval.

J. Schildmann: conception of manuscript, drafting the manuscript, final approval.

J. Weis: drafting the manuscript, final approval.

M. Wilhelm: drafting the manuscript, final approval.

C.M. Witt: drafting the manuscript, final approval.

M. Horneber: conception of manuscript, drafting the manuscript, final approval.

\section{References}

1 Horneber M, Bueschel G, Dennert G, Less D, Ritter E, Zwahlen M. How many cancer patients use complementary and alternative medicine: a systematic review and metaanalysis. Integr Cancer Ther. 2012 Sep;11(3):187203.

2 Bishop FL, Prescott P, Chan YK, Saville J, von Elm E, Lewith GT. Prevalence of complementary medicine use in pediatric cancer: a systematic review. Pediatrics. 2010 Apr;125(4): 768-76.

3 Vincent C, Furnham A. Why do patients turn to complementary medicine? An empirical study. Br J Clin Psychol. 1996 Feb;35(Pt 1): 37-48.

4 Tautz E, Momm F, Hasenburg A, Guethlin C. Use of complementary and alternative medicine in breast cancer patients and their experiences: a cross-sectional study. Eur J Cancer. 2012 Nov;48(17):3133-9.

5 Wanchai A, Armer JM, Stewart BR. Complementary and alternative medicine use among women with breast cancer: a systematic review. Clin J Oncol Nurs. 2010 Aug;14(4):E4555.

6 Williams JT. Credible complementary and alternative medicine websites. J Adv Pract Oncol. 2013 Mar;4(2):123-4.

7 Laengler A, Spix C, Seifert G, Gottschling S, Graf N, Kaatsch P. Complementary and alternative treatment methods in children with cancer: A population-based retrospective survey on the prevalence of use in Germany. Eur J Cancer. 2008 Oct;44(15):2233-40.

8 Davis EL, Oh B, Butow PN, Mullan BA, Clarke S. Cancer patient disclosure and patient-doctor communication of complementary and alternative medicine use: a systematic review. Oncologist. 2012;17(11):147581.
9 Schofield P, Diggens J, Charleson C, Marigliani R, Jefford M. Effectively discussing complementary and alternative medicine in a conventional oncology setting: communication recommendations for clinicians. Patient Educ Couns. 2010 May;79(2):143-51.

10 Horneber M, van Ackeren G, Fischer F, Kappauf H, Birkmann J. Addressing Unmet Information Needs: Results of a ClinicianLed Consultation Service About Complementary and Alternative Medicine for Cancer Patients and Their Relatives. Integr Cancer Ther. 2018 Dec;17(4):1172-82.

11 Witt CM, Bartsch HH, Guethlin C, Lampert C, Längler A, Ritter CA, et al. Kompetenznetz Komplementärmedizin in der Onkologie (KOKON). Forum. 2017;16:843.

12 Wahl S, Grimm M. How to Find an Alternative: A Typology of Cancer Patients' Information Behavior with Regard to Complementary and Alternative Medicine. Int J Commun Health. 2016;10. Available from: http://communicationandhealth.ro/upload/number10/ STEFANIE-WAHL.pdf

13 Gschwendtner KM, Klein G, Güthlin C, Holmberg C, Horneber M, Weis J. Bedeutung komplementärmedizinischer Verfahren bei Patienten mit Prostatakarzinom. Urologe A. 2014 Nov;53(11):1600-9.

14 Gschwendtner KM, Holmberg C, Weis J. Beweggründe von Krebspatienten für und gegen die Inanspruchnahme der Misteltherapie. Forsch Komplement Med. 2016;23(4):21522.

15 Klein GE, Guethlin C. Information and Training Needs Regarding Complementary and Alternative Medicine: A Cross-sectional Study of Cancer Care Providers in Germany. Integr Cancer Ther. 2018 Jun;17(2): $380-7$.
16 Corina G, Christine H, Klein G. Oncologists' experiences of discussing complementary and alternative treatment options with their cancer patients. A qualitative analysis. Support Care Cancer. 2016 Sep;24(9):3857-62.

17 Blödt S, Mittring N, Schützler L, Fischer F, Holmberg C, Horneber M, et al. A consultation training program for physicians for communication about complementary medicine with breast cancer patients: a prospective, multi-center, cluster-randomized, mixedmethod pilot study. BMC Cancer. 2016 Nov; 16(1):843.

18 Ritter CA, Ziemann J, Pufahl L, Efferth T, Horneber M. Strategies to assess drug interactions in oncology. Oncol Res Treat. 2018;41: 267.

19 Ziemann J, Lendeckel A, Müller S, Horneber M, Ritter CA. Herb-drug interactions: a novel algorithm-assisted information system for pharmacokinetic drug interactions with herbal supplements in cancer treatment. Eur J Clin Pharmacol. 2019 Sep;75(9):1237-1248.

20 Helmer SM, Rogge AA, Fischer F, Pach D, Horneber M, Roll S, et al. Evaluation of a blended-learning training concept to train oncology physicians to advise their patients about complementary and integrative medicine (KOKON-KTO): study protocol for a prospective, multi-center, cluster-randomized trial. Trials. 2019 Jan;20(1):90.

21 Roter D, Larson S. The Roter interaction analysis system (RIAS): utility and flexibility for analysis of medical interactions. Patient Educ Couns. 2002 Apr;46(4):243-51.

22 Juraskova I, Hegedus L, Butow P, Smith A, Schofield P. Discussing complementary therapy use with early-stage breast cancer patients: exploring the communication gap. Integr Cancer Ther. 2010 Jun;9(2):168-76. 